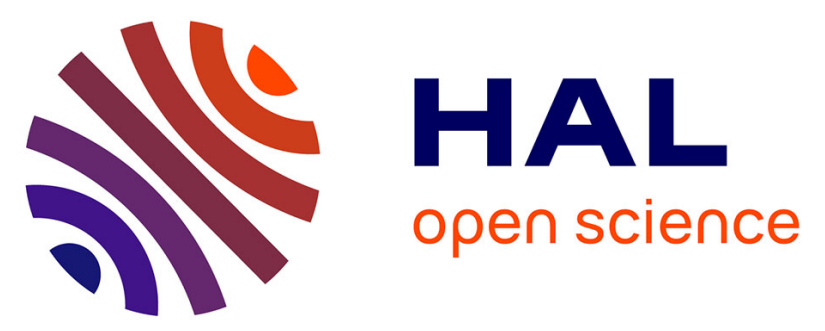

\title{
Nasal carriage of in healthy humans with different levels of contact with animals in Tunisia: genetic lineages, methicillin resistance, and virulence factors
}

\author{
K. Ben Slama, H. Gharsa, N. Klibi, A. Jouini, C. Lozano, E. Gómez-Sanz, M. \\ Zarazaga, A. Boudabous, C. Torres
}

\section{To cite this version:}

K. Ben Slama, H. Gharsa, N. Klibi, A. Jouini, C. Lozano, et al.. Nasal carriage of in healthy humans with different levels of contact with animals in Tunisia: genetic lineages, methicillin resistance, and virulence factors. European Journal of Clinical Microbiology and Infectious Diseases, 2010, 30 (4), pp.499-508. 10.1007/s10096-010-1109-6 . hal-00640232

\section{HAL Id: hal-00640232 https://hal.science/hal-00640232}

Submitted on 11 Nov 2011

HAL is a multi-disciplinary open access archive for the deposit and dissemination of scientific research documents, whether they are published or not. The documents may come from teaching and research institutions in France or abroad, or from public or private research centers.
L'archive ouverte pluridisciplinaire HAL, est destinée au dépôt et à la diffusion de documents scientifiques de niveau recherche, publiés ou non, émanant des établissements d'enseignement et de recherche français ou étrangers, des laboratoires publics ou privés. 
Nasal carriage of Staphylococcus aureus in healthy humans with different level of contact with animals in Tunisia: genetic lineages, methicillin-resistance and virulence factors.

Karim Ben Slama ${ }^{1}$, Haythem Gharsa ${ }^{1}$, Naouel Klibi ${ }^{1}$, Ahlem Jouini ${ }^{1}$, Carmen Lozano ${ }^{2}$, Elena Gómez-Sanz ${ }^{2}$, Myriam Zarazaga ${ }^{2}$, Abdellatif Boudabous ${ }^{1}$ and Carmen Torres ${ }^{2}$

${ }^{1}$ Laboratoire Microorganismes et Biomolécules Actives, Faculté de Sciences de Tunis, Université Tunis- El Manar, 2092 Tunis, Tunisia; ${ }^{2}$ Área de Bioquímica y Biología Molecular, Universidad de La Rioja, Logroño, Spain.

Running title: Nasal carriage of MRSA in healthy humans in Tunisia

Keywords: MRSA, MLST, PVL, TSST, Tunisia

\section{Corresponding author:}

Carmen Torres

Área de Bioquímica y Biología Molecular

Universidad de La Rioja

Madre de Dios, 51

26006 Logroño, Spain

FAX: 34-941299721: Phone: 34-941299750, E-MAIL: carmen.torres@ unirioja.es 


\begin{abstract}
Nasal swabs of 423 healthy-humans who showed different level of contact with animals (frequent, 168; sporadic, 94; no contact, 161) were obtained in Tunisia (2008-2009), and 99 of them presented other associated risk factors. Methicillin-resistant S. aureus (MRSA) was detected in one of these 423 samples $(0.24 \%)$, retrieved from a veterinarian. MRSA isolate was mecA-positive, typed as ST80-t203-SCCmecIVc-agrIII, and contained tet(K), ant(6)-Ia and $\operatorname{aph}\left(3^{\prime}\right)$-IIIa genes encoding tetracycline, streptomycin and kanamycin resistance, respectively. This MRSA isolate also contained the lukF/lukS virulence gene encoding Panton-Valentine leukocidin. Fifty-four (12.8\%) additional nasal samples contained methicillin-susceptible $S$. aureus and one isolate/sample was characterized. A high diversity of spa-types ( $\mathrm{n}=43 ; 4$ new) and PFGE-types $(\mathrm{n}=37)$ was detected among the 55 recovered $S$. aureus. Percentages of antimicrobial resistance/detected resistant genes were as follows: tetracycline [22\%/tet $(K)-\operatorname{tet}(L)-\operatorname{tet}(M)]$, erythromycin [5\%/msrA], ciprofloxacin [14.5\%], trimethoprim-sulfamethoxazole [2\%/dfrA], streptomycin [11\%/ant(6)-Ia], kanamycin [7\%/aph(3')-IIIa], amikacin [5\%], and chloramphenicol [2\%]. Four and two isolates carried the $l u k F / l u k S$ and $e t a$ and/or $e t b$ genes, respectively, and always in individuals with contact with animals. Eleven isolates carried the tst gene and were recovered from individuals with different level of contact with animals.
\end{abstract}




\section{Introduction}

Nosocomial infections caused by Staphylococcus aureus constitute an important health problem worldwide. This microorganism is usually associated with skin and soft tissue infections. However, it is also able to cause serious diseases such as pneumonia, meningitis or septicemia. Additionally, the pathogenicity of $S$. aureus infections is facilitated by the expression of several virulence factors which include cell wall-associated adhesins and several toxin groups $[1,2]$.

Of particular concern is methicillin-resistant S. aureus (MRSA), which has become a major threat due to an increasing incidence since its first report in 1961. First MRSA infections were facilitated by several predisposing factors including recent hospitalisation, admission to an Intensive Care Unit (ICU), prolonged antibacterial therapy or surgery. MRSA strains acquired in these environments are known as hospital acquired MRSA (HA-MRSA) [3]. The presence of multiple antimicrobial resistance in S. aureus isolates, common trait among HA-MRSA strains, is an important clinical problem limiting therapeutic options [4].

The first cases of MRSA in the community setting were reported in the early 1990s from patients without the aforementioned risk factors. These strains are well known as community acquired MRSA (CA-MRSA) [5]. Currently, CA-MRSA infections occur among healthy persons without risk factors for HA-MRSA acquisition, being reported at an increasing frequency having a worldwide distribution. These infections seem to be caused by isolates that differ from typical HA-MRSA by their genetic background, epidemiology, clinical spectrum, antibacterial resistance and by the presence of determined toxin genes [6]. For example, CA-MRSA isolates are more likely than HA-MRSA isolates to encode putative virulence factors, such as Panton-Valentine leukocidin (PVL), a cytotoxic virulence factor that has been associated with severe pneumonia and with skin and soft tissue infections [6-8]. In the last years, a livestock-associated genetic lineage of MRSA of the sequence type ST398 
has emerged in farm animals, especially in pigs, and human infections due to this specific type of MRSA have also been reported [9-11].

So far, few data do exist about the prevalence of MRSA in nasal samples of healthy population or about the genetic lineages of $S$. aureus that colonize the nares of healthy humans. A previous study carried out in USA reported a MRSA carriage rate in healthy humans of about $0.84 \%$ [12]. Another study carried out in the Netherlands among healthcare workers with and without exposition to livestock, detected MRSA carriage rates of $1.7 \%$ and $0.15 \%$, respectively [13]. It is known that nasal carriage of $S$. aureus has been identified as a risk factor for the development of infections at the hospital level, and if the microorganism is methicillin-resistant, it can cause serious health problems. Few studies have focused on which individuals are most likely to be colonized with $S$. aureus and which are most likely to specifically have MRSA. Likewise, little is known on the potential influence of animal contact for the acquisition of animal and non-animal associated S. aureus strains.

Therefore, the present study was undertaken to determinate the nasal carriage of MRSA and S. aureus in healthy individuals in order to identify whether the intensity of animal contact might be a risk factor for the acquisition of MRSA or other specific types of S. aureus strains. Likewise, we aimed to determinate the characteristics of the obtained strains using different molecular techniques including its clonal diversity.

\section{Materials and methods}

\section{Study design and sampling}

Nasal swabs of 423 healthy individuals were obtained in different regions of Tunisia from October 2008 to February 2009. Each of the individuals was asked to provide information about the level of contact with farm or companion animals (frequent, sporadic or no contact) and also about the use of antimicrobials or contact with hospitalized patients during the three months prior to the sample time. 


\section{Microbiological isolation}

All swabs were incubated in Tryptone Soy Broth (TSB) for $48 \mathrm{~h}$ and then, broths were subcultured on ORSAB medium (Oxacillin Resistance Screening Agar Base) (Oxoid, UK) for 24-48 hours. S. aureus compatible colonies were initially identified by conventional methods [Gram-staining, catalase test, oxidase test and DNase production, and ability to coagulate rabbit plasma (BioRad, France)]. Species identification was then confirmed by speciesspecific PCR amplification of the nuc and spa genes [14].

\section{Antimicrobial susceptibility testing}

Susceptibility to 17 antimicrobial agents was performed using the disk-diffusion method in accordance with the Clinical and Laboratory Standards Institute recommendations [15]. Antimicrobial agents tested were (charge in $\mu \mathrm{g}$ ): oxacillin (1), cefoxitin (30), kanamycin (30), gentamicin (10), tobramycin (10), tetracycline (30), chloramphenicol (30), trimethoprimsulfamethoxazole (1.25/23.75), erythromycin (15), clindamycin (2), amikacin (30), ciprofloxacin (5), mupirocin (5), vancomycin (30), teicoplanin (30), and penicillin and streptomycin (10 units). Double-disk diffusion test (D-test) with erythromycin and clindamycin discs was implemented in all isolates to detect inducible clindamycin resistance. Minimum inhibitory concentrations (MICs) for vancomycin and teicoplanin were performed by the agar dilution method [15]. S. aureus ATCC 25923 and ATCC 29213 and Enterococcus faecalis ATCC 29212 were used as control strains.

\section{Detection of mecA gene and SCCmec-typing}

The presence of the mecA gene was studied by PCR in all oxacillin and/or cefoxitin resistant isolates, as previously described [16]. The SCCmec-typing was performed for mecA positive isolates by a multiplex PCR strategy as previously described [17].

\section{Detection of antimicrobial resistance genes}


The ribosomal methylases encoded by $\operatorname{erm}(A) \operatorname{erm}(B)$ and $\operatorname{erm}(C)$ genes, which confer resistance to erythromycin and clindamycin, and the efflux pump encoded by $\operatorname{msr}(A)$ gene, conferring resistance to erythromycin, were studied by PCR in erythromycin-resistant isolates $[18,19]$. In addition, $\operatorname{tet}(K), \operatorname{tet}(M)$ and $\operatorname{tet}(L)$ genes, conferring resistance to tetracycline, and $a a c\left(6^{\prime}\right)-I e-a p h\left(2^{\prime \prime}\right)-I a, a p h\left(3^{\prime}\right)-I I I a$, and $\operatorname{ant}(6)-I a$ genes, conferring resistance to gentamicin, kanamycin and streptomycin, respectively, were amplified by PCR in all aminoglycosideresistant $S$. aureus isolates [20,21]. The presence of genes associated with resistance to trimethoprim-sulfamethoxazole $(d f r A$ and $d f r D)$ and chloramphenicol [cat(pC194), $\operatorname{cat}(\mathrm{pC} 221), \operatorname{cat}(\mathrm{pC} 223)]$ were analysed by PCR as previously reported [22].

\section{Pulsed-Field-Gel-Electrophoresis (PFGE)}

All S. aureus isolates were characterized by PFGE with SmaI restriction enzyme digestion as previously described [23]. The samples were run on $1 \%$ agarose gel in $0.5 \%$ TBE buffer at $14^{\circ} \mathrm{C}$ on a CHEF DR-II PFGE system by using an initial switching time of 5 s which was increased to $40 \mathrm{~s}$ during $20 \mathrm{~h}$ at $6 \mathrm{~V} / \mathrm{cm}$. The DNA fingerprints generated by PFGE were analyzed with manual method according to previous proposed criteria [24], and digitalized method by Gel-Pro version 3.1 software. The obtained results were submitted to multivariate statistical package (MVSP) software generating dendrogram according to simple matching coefficient and unweighted pair group method with arithmetic mean (UPGMA) algorithm.

Other molecular typing methods of $\mathrm{S}$. aureus isolates

Spa-typing was performed in all S. aureus isolates as elsewhere described [25]. The X region of spa gene was amplified by PCR, and sequences were analyzed using Ridom Staph-Type software version 1.5.21 (Ridom $\mathrm{GmbH}$ ), which automatically detects spa repeats and assigns a spa-type according to http://spaserver.ridom.de/.

Identification of agr allele group (I-IV) was determined by multiplex PCR. The nucleotide sequence of each primer and the amplification conditions were as earlier described [26]. 
Multilocus-sequence-typing (MLST) was performed in selected S. aureus isolates (those containing the genes of the Panton-Valentine Leukocidin (PVL), and those presenting new spa-types) as described previously [27]. The allelic profile of each strain was obtained by sequencing internal fragments of seven unlinked housekeeping genes ( $\operatorname{arc} C, \operatorname{aroE}, g l p F, g m k$, $p t a, t p i$, and $y q i L)$. Alleles of the 7 genes defined the allelic profile, which corresponded to a sequence type (ST) assigned by the MLST database (http://www.mlst.net).

\section{Detection of staphylococcal toxin genes}

All isolates were tested by PCR for the presence of four staphylococcal toxin genes [28]. The targeted genes were the following ones: lukS-lukF encoding the PVL toxin, eta and etb encoding exfoliative toxins ETA and ETB, respectively, and tst encoding the toxic shock syndrome toxin (TSST).

\section{Results}

Table 1 shows the characteristics of the 423 individuals tested in relation with the level of contact with animals and other risk factors. Individuals included in the study were classified into four groups: 1) frequent contact with farm animals (veterinarians, veterinary students, farmers and abattoir-workers) $(\mathrm{n}=111) ; 2)$ high contact with companion animals $(\mathrm{n}=57) ; 3)$ sporadic contact with animals $(n=94) ; 4)$ no contact with animals $(n=161)$. Ninety-nine of these individuals had other risk factors as previous contact with hospitalised patients or use of antibiotic in the three months prior sampling (Table 1).

\section{Carriage of MRSA and typing of isolates}

The nasal swabs of all 423 individuals tested were analysed for MRSA recovery and only one contained a mecA-positive MRSA isolate, representing $0.24 \%$ of the total number of tested samples. This MRSA isolate (C2444) was recovered from a veterinarian and showed a phenotype of resistance that included, in addition to beta-lactams, resistance to tetracycline, 
streptomycin and kanamycin, and harboured the tet(K), ant(6)-Ia, and aph(3')-IIIa genes. MRSA C2444 was typed as SCCmec type IVc, and was ascribed to the agr-type III, to the spa-type t203 and to the MLST type ST80. It is interesting to remark that the genes encoding the PVL toxin were identified in this strain, but not the other tested toxin genes (tst, eta and $e t b)$.

Detection of $S$. aureus and characterization of antimicrobial resistance mechanisms and virulence genes

S. aureus was recovered in 55 of the 423 nasal samples tested and one isolate per sample was maintained for further studies. The origin of the $55 \mathrm{~S}$. aureus isolates and their antimicrobial resistance patterns are shown in Table 2. All isolates exhibited penicillin resistance, although only one of them showed oxacillin and cefoxitin resistance by disk-diffusion test and the mecA gene was identified in this isolate (MRSA C2444, recovered from the veterinarian previously indicated). Seventeen additional $S$. aureus isolates exhibited resistance to oxacillin but not to cefoxitin and all of them were negative for mecA gene. The remaining $37 \mathrm{~S}$. aureus isolates showed oxacillin-susceptibility even though they were recovered in ORSAB medium. All 55 S. aureus isolates showed susceptibility to vancomycin, teicoplanin, gentamicin, tobramycin, clindamycin and mupirocin, showing MICs for vancomycin and teicoplanin of $\leq 1 \mu \mathrm{g} / \mathrm{ml}$.Variable resistance rates were observed to tetracycline (21.8\%), ciprofloxacin (16.4\%), streptomycin (10.9\%), kanamycin (7.3\%), erythromycin and amikacin $(5.4 \%$ each one), and trimethoprim-sulfamethoxazole and chloramphenicol (1.8\% each one). No inducible clindamycin resistance was identified in the three erythromycin-resistant S. aureus isolates when the double-disk erythromycin-clindamycin screening test was used.

The $t s t$ gene, encoding the toxic shock toxin, was detected in 11 of 55 isolates (20\%). Other toxin genes detected included the $l u k S$-lukF genes encoding the Panton-Valentin-leukocidin toxin detected in 4 of 55 studied $S$. aureus isolates (7.3\%), and the eta and etb genes, 
encoding the exfoliative ETA and ETB toxins, respectively, harboured by two isolates. All four S. aureus isolates carrying the genes of PVL toxin were obtained from individuals with high contact with animals $(n=3)$ or with sporadic contact with animals $(n=1)$, but no PVLpositive isolate was identified in the group of individuals with no contact with animals. It is important to note that isolate $\mathrm{C} 2431$ is characterized by a high virulence potential, since it produced both exfolitive toxin ETA and ETB, and it was recovered from an individual that had taken antimicrobial agents in the previous months and had also contact with hospitalised patients and with animals.

No correlation was found between the presence of virulence genes and antimicrobial resistance. It is important to note that in our study, almost half of $S$. aureus obtained from individuals that referred high contact with farm or companion animals harboured genes encoding virulence factors but only $13 \%$ of isolates of individuals with no contact with animals presented this characteristic.

Molecular typing of S. aureus isolates and detection of virulence genes

All 55 S. aureus isolates were submitted to molecular typing by spa, agr and PFGE techniques, and some selected S. aureus isolates were also submitted to MLST typing, and results are shown in Table 2 .

Analysis of SmaI macrorestriction profiles revealed a high clonal diversity with 37 unique PFGE patterns (Figure 1). These patterns were classified from S1 to S37, each defining a clone in accordance to the previous reported interpretive criteria [24]. The pulsotype S34 was the most frequently encountered one (7.3\% of isolates, 4 isolates). Two isolates with S6 pulsotype produced exfoliative toxins (ETA and/or ETB). Four of 11 isolates harboured the tst gene and belonged to pulsotype S2. The four PVL producing $S$. aureus isolates were ascribed to four different pulsotypes (S4, S19, S23 and S25). 
Among the high diverse spa gene types $(\mathrm{n}=43)$, four not earlier described types were identified (t6222, t6223, t6224, and t6225). Spa-typing analysis results confirmed those previously found in the analysis by PFGE: 1) isolates C2410 and C2425 belonging to pulsotype S35 presented the same spa-type t166;2) two isolates which shared the same t024 spa-type belonged to pulsotype S5 (C2447 and C2442); 3) two isolates with identical pulsotype S7 (C2440 and C2432) shared the common spa-type t084. There was no clear association between the spa type and the antimicrobial resistance pattern.

Amplification of the hypervariable region of the agr locus showed that agr group I was predominant (detected in 21 of 55 S. aureus isolates, 38.2\%), followed by agr groups II and III (20\% each), and agr group IV (1.8\%). However, 11 isolates were untypable (20\%).

All 4 PVL-positive $S$. aureus isolates and the four isolates presenting new spa-types were analysed by MLST and they were compared with the $S$. aureus MLST database. All eight $S$. aureus isolates belonged to 7 different already known sequence types, and a new sequence type ST1704 was also identified for S. aureus C2459 that presented the new spa-type t6225 (Table 1).

PFGE revealed remarkable clonality among isolates producing the virulence factor TSST-1, and also among those producing the exfoliatin A and B. However, no clonal relationship has been detected among the four isolates in which the genes of the PVL toxin have been demonstrated (Figure 1).

\section{Discussion}

The rate of MRSA nasal carriage seems to be very low in healthy individuals in Tunisia, as only one person of 423 tested was positive for MRSA $(0.24 \%)$, although the initial number of positive cultures on the selective ORSAB medium suggested a much higher prevalence. It is interesting to remark that the MRSA-positive person was a veterinarian who worked with farm animals, and if we consider only the group of individuals with high contact with farm 
animals, the rate of nasal carriage is a little higher ( 1 out of $113,0.9 \%)$. Studies performed in other countries also show low nasal carriage of MRSA among the healthy population [29], although this prevalence seems to be higher among persons in contact with farm animals [30,31]. It is interesting to point out that the MRSA strain recovered in our study presented a multiresistant antimicrobial phenotype that included not only beta-lactams, but also aminoglycosides and tetracycline. Molecular typing revealed that MRSA strain C2444 belonged to ST80 and was characterized by cassette SCCmec type IVc, agr type III and with PVL toxin production. All these characteristics are in line with those of the major PVLpositive CA-MRSA clone detected in many European countries. Today, the ST80 PVLpositive CA-MRSA clone is disseminated in Asia, Europe and the Middle-East [32]. However, the spa-type related to the MRSA isolate in our study was t203, which remains different from that of the European clone ST80 which is normally of spa-type t044 [32, 33]. Nevertheless, both spa-types are very similar, the spa-type t203 presenting an extra repeat (r12). The agr III/ST80 lineage detected in our study in MRSA strain C2444 has also been reported as one of the predominant lineages of PVL-positive MSSA [34,35]. PVL production is considered as a common trait among CA-MRSA but it is important to recognize that PVLnegative strains can also occur.

In this study it has been detected that all the PVL-positive $S$. aureus isolates were recovered in individuals that had contact with animals, but not among those without contact with animals. It is interesting to remark that these strains (the MRSA strain above mentioned as well as the three MSSA ones) were not clonally related and they presented different spa, PFGE and MLST types, indicating no clonal relationship among them. The association of PVL-production with ST30, ST121 or ST22 lineages in three of our MSSA strains has been previously identified as some of the most prevalent lineages of PVL-positive MSSA in different countries [34, 35, 36]. Moreover, sequence type ST30 constitute one of the predominant CA-MRSA clones in Australian and South American isolates [37]. Nevertheless, 
the ST121 lineage may have a global distribution and it is more frequently associated to MSSA [36], although it has also been recently detected in cases of CA-MRSA [38].

PVL-encoding genes had been detected in strains representing the majority of agr groups (I, III and IV) and belonging to widely distributed STs [34]. The observed diversity of PVLpositive strains might be attributed to the fact that PVL genes are localised on phages, which facilitate spread of PVL genes through S. aureus populations [39].

Remarkably, the chromogenic medium intended for selective MRSA recovery also allowed the recovery of oxacillin-susceptible $S$. aureus isolates in some of the nasal samples. It is of interest to remark the low specificity of this media for MRSA recovery as previously reported by other authors [40], as well as the importance of further characterizing isolates grown in this media with the appearance of MRSA.

A high clonal diversity was identified among the 55 S. aureus isolates obtained in this study (54 MSSA and one MRSA) reflected by 43 different spa-types and 37 different PFGE patterns. In addition, 8 different sequence-types were identified by MLST among 8 selected S. aureus isolates (4 isolates PVL-positive and 4 isolates with new spa-types). Seventeen $S$. aureus isolates among the 55 recovered in this study (30.9\%) showed oxacillin-resistance but cefoxitin-susceptibility and did not carry the mecA gene; the presence of other mechanisms of resistance can not be discarded in these mecA-negative strains, as it is the case of hyperproduction of penicilinase or modification of other PBP's [41].

Besides the PVL encoding genes, three other toxin genes were detected among S. aureus strains: tst (11 isolates), eta (2 isolates) and etb (1 isolate). This finding might have implications in human health.

Previous investigations reported that agr groups of $S$. aureus were associated with the patterns of S. aureus diseases [28]. They reported that isolates of agr group I and II caused preferentially diseases mediated by enterotoxin and that agr group III isolates were involved in TSST-1 mediated diseases. In our study, a strong relationship was observed between agr 
group III and toxic shock toxin TSST-1. Similarly, we also noted that 2 isolates among the four harbouring $l u k S-P V$ and $l u k F-P V$ genes belonged to the same agr group III.

This study is the first one that reports both, the rate of nasal carriage by MRSA and the nasal carriage of PVL-positive or TSST-positive S. aureus in healthy humans, not only in Tunisia but also in the African continent. In this study, MRSA and PVL-positive S. aureus isolates (both MRSA and MSSA) were detected mostly among individuals in contact with animals. More studies should be performed in the future, including more individuals with different risk factors, in order to assess the risk of contact with animals in relation with the possibility of being a nasal carrier of this specific microorganism, as well as the risk for acquisition of staphylococcal infections.

\section{Acknowledgement}

This study has been possible thank to an Integrated Action and a project financed by the Spanish Agency of International Collaboration (AECID) from the Ministerio de Asuntos Exteriores of Spain and from the Tunisian Ministry of Higher Education and Scientific Research. C. Lozano has a predoctoral fellowship form the Ministery of Science and Innovation and E. Gómez-Sanz a predoctoral fellowship from the Gobierno of Rioja, Spain.

Part of the results of this manuscript has been presented in the $50^{\text {th }}$ InterScience Conference on Antimicrobial Agents and Chemotherapy (ICAAC) held in Boston 12-15 September 2010.

\section{References}

1. Somerville GA, Proctor RA (2009) At the crossroads of bacterial metabolism and virulence factor synthesis in staphylococci. Microbiol Mol Biol Rev 73:233-48

2. Dinges MM, Orwin PM, Schlievert PM (2000) Exotoxins of Staphylococcus aureus. Clin Microbiol Rev 13:16-34 
3. Maltezou HC, Giamarellou H (2006) Community-acquired methicillin-resistant Staphylococcus aureus infections. Int J Antimicrob Agents 27:87-96

4. Fluit AC, Wielders CL, Verhoef J, Schmitz FJ (2001) Epidemiology and susceptibility of 3,051 Staphylococcus aureus isolates from 25 university hospitals participating in the European Sentry Study. J Clin Microbiol 39:3727-3732

5. Deresinski S (2005) Methicillin-resistant Staphylococcus aureus: An evolutionary, epidemiologic, and therapeutic odyssey. Clin Infect Dis 40:562-573

6. Naimi TS, LeDell KH, Boxrud DJ, Groom AV, Steward CD, Johnson SK, Besser JM, O'Boyle C, Danila RN, Cheek JE, Osterholm MT, Moore KA, Smith KE (2001) Epidemiology and clonality of community-acquired methicillin-resistant Staphylococcus aureus in Minnesota, 1996-1998. Clin Infect Dis 33:990-996

7. Regev-Yochay G, Rubinstein E, Barzilai A, Carmeli Y, Kuint J, Etienne J, Blech M, Smollen G, Maayan-Metzger A, Leavitt A, Rahav G, Keller N (2005) Methicillinresistant Staphylococcus aureus in neonatal intensive care unit. Emerg Infect Dis $11: 453-456$

8. Naimi TS, LeDell KH, Como-Sabetti K, Borchardt SM, Boxrud DJ, Etienne J, Johnson SK, Vandenesch F, Fridkin S, O'Boyle C, Danila RN, Lynfield R (2003) Comparison of community- and health care-associated methicillin-resistant Staphylococcus aureus infection. JAMA 290:2976-2984

9. van Loo I, Huijsdens X, Tiemersma E, de Neeling A, van de Sande-Bruinsma N, Beaujean D, Voss A, Kluytmans J (2007) Emergence of methicillin-resistant Staphylococcus aureus of animal origin in humans. Emerg Infect Dis 13:1834-1839

10. Aspiroz C, Lozano C, Vindel A, Lasarte JJ, Zarazaga M, Torres C (2010) Skin lesion caused by ST398 and st1 methicillin-resistant Staphylococcus aureus in the daughter of a pig farmer in spain and MRSA colonization study in her family members. Emerg Infect Dis 16:157-159 
11. Kock R, Harlizius J, Bressan N, Laerberg R, Wieler LH, Witte W, Deurenberg RH, Voss A, Becker K, Friedrich AW (2009) Prevalence and molecular characteristics of methicillin-resistant Staphylococcus aureus (MRSA) among pigs on German farms and import of livestock-related MRSA into hospitals. Eur J Clin Microbiol Infect Dis 28:1375-1382

12. Mainous AG, 3rd, Hueston WJ, Everett CJ, Diaz VA (2006) Nasal carriage of Staphylococcus aureus and methicillin-resistant S. aureus in the United States, 20012002. Ann Fam Med 4:132-137

13. Wulf MW, Tiemersma E, Kluytmans J, Bogaers D, Leenders AC, Jansen MW, Berkhout J, Ruijters E, Haverkate D, Isken M, Voss A (2008) MRSA carriage in healthcare personnel in contact with farm animals. J Hosp Infect 70:186-190

14. Lozano C, Lopez M, Gomez-Sanz E, Ruiz-Larrea F, Torres C, Zarazaga M (2009) Detection of methicillin-resistant Staphylococcus aureus ST398 in food samples of animal origin in Spain. J Antimicrob Chemother 64:1325-1326

15. CLSI (2008) Performance standards for antimicrobial susceptibility testing; eighteenth informational supplement. CLSI document M100-18 CLSI, Wayne, Pennsylvania, USA

16. Zhang K, Sparling J, Chow BL, Elsayed S, Hussain Z, Church DL, Gregson DB, Louie T, Conly JM (2004) New quadriplex pcr assay for detection of methicillin and mupirocin resistance and simultaneous discrimination of Staphylococcus aureus from coagulase-negative staphylococci. J Clin Microbiol 42:4947-4955

17. Kondo Y, Ito T, Ma XX, Watanabe S, Kreiswirth BN, Etienne J, Hiramatsu K (2007) Combination of multiplex PCRs for staphylococcal cassette chromosome mec type assignment: Rapid identification system for mec, $c c r$, and major differences in junkyard regions. Antimicrob Agents Chemother 51:264-274 
18. Wondrack L, Massa M, Yang BV, Sutcliffe J (1996) Clinical strain of Staphylococcus aureus inactivates and causes efflux of macrolides. Antimicrob Agents Chemother 40:992-998

19. Sutcliffe J, Grebe T, Tait-Kamradt A, Wondrack L (1996) Detection of erythromycinresistant determinants by PCR. Antimicrob Agents Chemother 40:2562-2566

20. Aarestrup FM, Agerso Y, Gerner-Smidt P, Madsen M, Jensen LB (2000) Comparison of antimicrobial resistance phenotypes and resistance genes in Enterococcus faecalis and Enterococcus faecium from humans in the community, broilers, and pigs in Denmark. Diagn Microbiol Infect Dis 37:127-137

21. Van de Klundert JAM, Vliegenthart JS (1993) Pcr detection of genes coding for aminoglycoside-modifying enzymes. In: Persing DH, Smith TF, Tenover FC, Wite TJ (eds) Diagnostic molecular microbiology principles and applications. American Society for Microbiology, Washington, DC, pp 547-542

22. Schnellmann C, Gerber V, Rossano A, Jaquier V, Panchaud Y, Doherr MG, Thomann A, Straub R, Perreten V (2006) Presence of new mecA and $m p h(c)$ variants conferring antibiotic resistance in Staphylococcus spp. Isolated from the skin of horses before and after clinic admission. J Clin Microbiol 44:4444-4454

23. Bouzaiane O, Abbassi M, Gtari M, Belhaj O, Jedidi N, Ben Hassen A, Hassen A (2008) Molecular typing of staphylococcal communities isolated during municipal solid waste composting process Annals of Microbiology 58:387-394

24. Tenover FC, Arbeit RD, Goering RV, Mickelsen PA, Murray BE, Persing DH, Swaminathan B (1995) Interpreting chromosomal DNA restriction patterns produced by pulsed-field gel electrophoresis: Criteria for bacterial strain typing. J Clin Microbiol 33:2233-2239

25. Harmsen D, Claus H, Witte W, Rothganger J, Claus H, Turnwald D, Vogel U (2003) Typing of methicillin-resistant Staphylococcus aureus in a university hospital setting 
by using novel software for spa repeat determination and database management. J Clin Microbiol 41:5442-5448

26. Shopsin B, Herring S, Kreiswirth BN (2003) Hospital-acquired and communityderived: The future of MRSA? Clin Infect Dis 37:151-152; author reply 152

27. Enright MC, Day NP, Davies CE, Peacock SJ, Spratt BG (2000) Multilocus sequence typing for characterization of methicillin-resistant and methicillin-susceptible clones of Staphylococcus aureus. J Clin Microbiol 38:1008-1015

28. Jarraud S, Mougel C, Thioulouse J, Lina G, Meugnier H, Forey F, Nesme X, Etienne J, Vandenesch F (2002) Relationships between Staphylococcus aureus genetic background, virulence factors, agr groups (alleles), and human disease. Infect Immun $70: 631-641$

29. Bloomfield SF, Cookson B, Falkiner F, Griffith C, Cleary V (2007) Methicillinresistant Staphylococcus aureus, Clostridium difficile, and extended-spectrum betalactamase-producing Escherichia coli in the community: Assessing the problem and controlling the spread. Am J Infect Control 35:86-88

30. Loeffler A, Pfeiffer DU, Lloyd DH, Smith H, Soares-Magalhaes R, Lindsay JA (2010) Meticillin-resistant Staphylococcus aureus carriage in UK veterinary staff and owners of infected pets: New risk groups. J Hosp Infect 74:282-288

31. Van Cleef BA, Broens EM, Voss A, Huijsdens XW, Zuchner L, Van Benthem BH, Kluytmans JA, Mulders MN, Van De Giessen AW (2010) High prevalence of nasal MRSA carriage in slaughterhouse workers in contact with live pigs in the Netherlands. Epidemiol Infect 138:756-763

32. Deurenberg RH, Stobberingh EE (2008) The evolution of Staphylococcus aureus. Infect Genet Evol 8:747-763

33. Ben Nejma M, Mastouri M, Bel Hadj Jrad B, Nour M (2008) Characterization of ST80 Panton-Valentine leukocidin-positive community-acquired methicillin-resistant 
Staphylococcus aureus clone in tunisia. Diagn Microbiol Infect Dis doi:10.1016/j.diagmicrobio.2008.02.010.

34. Rasigade JP, Laurent F, Lina G, Meugnier H, Bes M, Vandenesch F, Etienne J, Tristan A (2010) Global distribution and evolution of Panton-Valentine leukocidinpositive methicillin-susceptible Staphylococcus aureus, 1981-2007. J Infect Dis 201:1589-1597

35. Monecke S, Slickers P, Ellington MJ, Kearns AM, Ehricht R (2007) High diversity of panton-valentine leukocidin-positive, methicillin-susceptible isolates of Staphylococcus aureus and implications for the evolution of community-associated methicillin-resistant S. aureus. Clin Microbiol Infect 13:1157-1164

36. Breurec S, Fall C, Pouillot R, Boisier P, Brisse S, Diene-Sarr F, Djibo S, Etienne J, Fonkoua MC, Perrier-Gros-Claude JD, Ramarokoto CE, Randrianirina F, Thiberge JM, Zriouil SB; the Working Group on Staphylococcus aureus infections, Garin B, Laurent F (2010) Epidemiology of methicillin-susceptible Staphylococcus aureus lineages in five major African towns: high prevalence of Panton-Valentine leukocidin genes. Clin Microbiol Infect. Jul 29. [Epub ahead of print]

37. Deurenberg RH, Vink C, Kalenic S, Friedrich AW, Bruggeman CA, Stobberingh EE (2007) The molecular evolution of methicillin-resistant Staphylococcus aureus. Clin Microbiol Infect 13:222-235

38. Cheng K, Tarquinio S, Wuthiekanun V, Sin L, Thaipadungpanit J, Amornchai P, Chanpheaktra N, Tumapa S, Putchhat H, Day NP, Peacock SJ (2009) Emergence of community-associated methicillin-resistant Staphylococcus aureus associated with pediatric infection in Cambodia. PLoS One 4:e6630

39. Kaneko J, Kimura T, Narita S, Tomita T, Kamio Y (1998) Complete nucleotide sequence and molecular characterization of the temperate staphylococcal bacteriophage phiPVL carrying Panton-Valentine Leukocidin genes. Gene 215:57-67 
40. Luteijn JM, Hubben GA, Pechlivanoglou P, Bonten MJ, Postma MJ (2010) Diagnostic accuracy of culture-based and PCR-based detection tests for methicillin-resistant Staphylococcus aureus: a meta-analysis. Clin Microbiol Infect Mar 6 [Epub ahead of print].

41. Torres C, Cercenado E (2010) Interpretive reading of the antibiogram in gram positive cocci. Enfermedades Infecciosas y Microbiología Clínica doi:10.1016/j.eimc.2010.02.003. 
Table 1. Characteristics of the 423 healthy individuals in relation with specific risk factors and characteristics of recovered $S$. aureus isolates.

\begin{tabular}{|c|c|c|c|c|c|}
\hline \multicolumn{2}{|c|}{ Characteristics of individuals tested } & \multirow{2}{*}{$\begin{array}{c}\text { No. } \\
\text { individuals } \\
\text { tested }\end{array}$} & \multirow{2}{*}{$\begin{array}{c}\text { No. } \\
\text { individuals } \\
\text { with } \text { S. aureus }\end{array}$} & \multirow{2}{*}{$\begin{array}{c}\text { No. }(\%) \\
\text { individuals } \\
\text { with MRSA } \\
\end{array}$} & \multirow{2}{*}{$\begin{array}{c}\text { Individuals with } \\
\text { toxigenic } S \text {. aureus } \\
\text { (No.) }\end{array}$} \\
\hline Contact with animals & $\begin{array}{c}\begin{array}{c}\text { Other risk } \\
\text { factors }^{\mathrm{a}}\end{array} \\
\end{array}$ & & & & \\
\hline \multirow{2}{*}{$\begin{array}{l}\text { High contact with farm } \\
\text { animals: veterinarian } \\
\text { students or staff; farmers; } \\
\text { abattoir workers }\end{array}$} & No & 83 & 16 & $1(1.2 \%)$ & $\begin{array}{c}\text { PVL (3) } \\
\text { TSST-1 (2) }\end{array}$ \\
\hline & Yes & 28 & 5 & 0 & $\mathrm{ETA}+\mathrm{ETB}(1)$ \\
\hline \multirow[t]{2}{*}{$\begin{array}{l}\text { High contact with } \\
\text { companion animals }\end{array}$} & No & 36 & 8 & 0 & $\begin{array}{c}\text { TSST-1 (4) } \\
\text { ETA (1) }\end{array}$ \\
\hline & Yes & 21 & 1 & 0 & \\
\hline \multirow{2}{*}{$\begin{array}{l}\text { Sporadic contact with } \\
\text { animals }\end{array}$} & No & 73 & 2 & 0 & PVL(1) \\
\hline & Yes & 21 & 1 & 0 & \\
\hline \multirow[t]{2}{*}{ No contact with animal } & No & 132 & 15 & 0 & TSST-1 (2) \\
\hline & Yes & 29 & 7 & 0 & TSST-1 (3) \\
\hline Total & & 423 & 55 & $1(0.2 \%)$ & (17) \\
\hline
\end{tabular}

${ }^{\mathrm{a}}$ Use of antibiotics or contact with hospitalised patients in the previous three months of sampling

${ }^{\mathrm{b}}$ PVL: Panton-Valentine leukocidin; ETA and ETB: exfoliative toxins A and B, respectively;

TSST: toxic shock syndrome toxin. 
Table 2. Phenotypic and genotypic characteristics of the 55 S. aureus isolates recovered from healthy individuals in relation with their specific risk factors

\begin{tabular}{|c|c|c|c|c|c|c|c|}
\hline S. aureus & Spa-type & MLST & $\begin{array}{l}\text { PFGE } \\
\text { profile }\end{array}$ & $\begin{array}{l}\text { agr } \\
\text { type }\end{array}$ & Toxins $^{\mathrm{a}}$ & $\begin{array}{l}\text { Phenotype of } \\
\text { antibiotic resistance }^{\text {b }}\end{array}$ & Resistance genes detected \\
\hline \multicolumn{8}{|c|}{ Frequent contact with farm animals: } \\
\hline $\mathrm{C} 2444$ & $\mathrm{t} 203$ & ST80 & S23 & III & PVL & PE-OX-FX-TE-ST-KA & mecA, tetK, ant(6)-Ia, aph(3')-IIIa) \\
\hline C2435 & $\mathrm{t} 318$ & ST30 & S19 & III & PVL & PE-TE & tet $K$ \\
\hline C2448 & t645 & ST121 & S25 & IV & PVL & PE-OX & \\
\hline $\mathrm{C} 2431^{\mathrm{c}}$ & t159 & & S6 & NT & ETA, ETB & PE-TE-ST & tet $K$ \\
\hline C2436 & $\mathrm{t} 046$ & & $\mathrm{~S} 2 \mathrm{~b}$ & III & TSST-1 & PE-TE & tet $K$ \\
\hline C2438 & t6222 & ST46 & S8a & I & TSST-1 & PE-OX & \\
\hline C2441 & t6223 & ST72 & S21 & I & & & \\
\hline $\mathrm{C} 2445^{\mathrm{d}}$ & t6224 & ST101 & S24 & II & & PE-OX-TE-K & tetK, $\operatorname{aph}\left(3^{\prime}\right)-I I I a$ \\
\hline C2430 & $\mathrm{t} 254$ & & S17 & NT & & PE-TE-ST-KA & $\operatorname{aph}\left(3^{\prime}\right)-I I I a$ \\
\hline C2442 & $\mathrm{t} 024$ & & S5 & I & & $\mathrm{PE}$ & \\
\hline C2447 & $\mathrm{t} 024$ & & S5 & I & & PE-CP & \\
\hline C2423 & t018 & & S2a & NT & & PE-OX & \\
\hline C2425 & $\mathrm{t} 166$ & & S35 & III & & PE & \\
\hline C2428 & t711 & & S16 & I & & PE-ST & \\
\hline C2433 & $\mathrm{t} 084$ & & S7 & II & & PE-TE & \\
\hline C2440 & t084 & & S7 & II & & PE-OX & tet $K$ \\
\hline C2434 & $\mathrm{t} 377$ & & S18 & I & & $\mathrm{PE}$ & \\
\hline C2437 & t346 & & S34 & NT & & PE & \\
\hline $\mathrm{C} 2439^{\mathrm{C}}$ & $\mathrm{t} 164$ & & S20 & I & & PE-TE-SX-ER & $d f r A$ \\
\hline $\mathrm{C} 2443^{\mathrm{c}}$ & $\mathrm{t} 1743$ & & S22 & I & & PE-OX & \\
\hline \multicolumn{8}{|c|}{ Frequent contact with companion animals } \\
\hline $\mathrm{C} 2420$ & $\mathrm{t} 254$ & & S6 & NT & ETA & PE-OX-ST-TE-KA-ER & $\left.\operatorname{tet} K, \operatorname{ant}(6)-I a, \operatorname{aph}\left(3^{\prime}\right)-I I I a\right)$ \\
\hline $\mathrm{C} 2455$ & $\mathrm{t} 012$ & & S3 & III & TSST-1 & PE-CIP & \\
\hline $\mathrm{C} 2456$ & $\mathrm{t} 012$ & & $\mathrm{~S} 2 \mathrm{~b}$ & III & TSST-1 & PE-OX & \\
\hline C2451 & $\mathrm{t} 018$ & & S3 & III & TSST-1 & PE-CP & \\
\hline $\mathrm{C} 2421$ & $\mathrm{t} 725$ & & S14 & NT & TSST-1 & PE-TE & \\
\hline $\mathrm{C} 2412$ & $\mathrm{t} 040$ & & S8b & I & & $\mathrm{PE}$ & \\
\hline $\mathrm{C} 2415$ & $\mathrm{t} 127$ & & S13 & III & & PE-CL & \\
\hline C2408 & t537 & & $\mathrm{S} 10$ & I & & PE & \\
\hline $\mathrm{C} 2409^{\mathrm{C}}$ & $\mathrm{t} 254$ & & $\mathrm{~S} 11$ & II & & $\mathrm{PE}$ & \\
\hline $\mathrm{C} 2426^{\mathrm{C}}$ & $\mathrm{t} 1268$ & & S36 & I & & PE & \\
\hline \multicolumn{8}{|c|}{ Sporadic contact with animals } \\
\hline $\mathrm{C} 2450$ & $\mathrm{t} 3638$ & ST22 & S4a & I & PVL & PE & \\
\hline C2454 & $\mathrm{t} 701$ & & S29 & I & & PE-CP & \\
\hline $\mathrm{C} 2452^{\mathrm{d}}$ & $\mathrm{t} 224$ & & S27 & I & & PE-OX & \\
\hline \multicolumn{8}{|c|}{ No contact with animals } \\
\hline C2411 & $\mathrm{t} 012$ & & S2a & NT & TSST-1 & PE-OX & \\
\hline C2460 & t5598 & & S33 & NT & TSST-1 & $\mathrm{PE}$ & \\
\hline $\mathrm{C} 2449^{\mathrm{d}}$ & $\mathrm{t} 223$ & & S26 & I & TSST-1 & PE-CP & \\
\hline $\mathrm{C} 2459^{\mathrm{d}}$ & t6225 & ST1704 & S32 & III & TSST-1 & $\mathrm{PE}$ & \\
\hline C2419 & $\mathrm{t} 674$ & & S34 & NT & TSST- 1 & PE-OX ST & $\operatorname{ant}(6)-I a$ \\
\hline C2429 & t002 & & $\mathrm{S} 1$ & II & & $\mathrm{PE}$ & \\
\hline C2413 & t008 & & S1 & I & & $\mathrm{PE}$ & \\
\hline C2446 & t094 & & S34 & II & & PE & \\
\hline C2416 & t279 & & S34 & NT & & PE & \\
\hline C2407 & $\mathrm{t} 127$ & & S1 & II & & PE-OX & \\
\hline C2427 & $\mathrm{t} 230$ & & S8a & I & & $\mathrm{PE}$ & \\
\hline C2424 & t701 & & $\mathrm{S} 8 \mathrm{~b}$ & I & & PE-OX & \\
\hline C2453 & $\mathrm{t} 311$ & & S28 & II & & PE-TE-CP & tet $L$, tetM \\
\hline C2417 & t559 & & S9 & II & & PE-OX-TE & \\
\hline C2457 & t587 & & S30 & NT & & PE-CP-ER & $m s r A$ \\
\hline C2406 & t922 & & S37 & III & & $\mathrm{PE}$ & \\
\hline C2414 & $\mathrm{t} 2883$ & & $\mathrm{~S} 12$ & I & & PE-OX & \\
\hline $\mathrm{C} 2432^{\mathrm{c}}$ & t095 & & S8a & I & & $\mathrm{PE}$ & \\
\hline
\end{tabular}




$\begin{array}{lllll}\mathrm{C} 2410 & \mathrm{t} 166 & \mathrm{~S} 35 & \text { III } & \text { PE } \\ \mathrm{C} 2422^{\mathrm{d}} & \mathrm{t} 166 & \mathrm{~S} 15 & \text { II } & \text { PE-OX } \\ \mathrm{C} 2458^{\mathrm{d}} & \mathrm{t} 166 & \mathrm{~S} 31 & \text { II } & \text { PE-OX-CP } \\ \mathrm{C} 2418^{\mathrm{d}} & \mathrm{t} 709 & \text { S4b } & \text { I } & \text { PE-OX-CP }\end{array}$

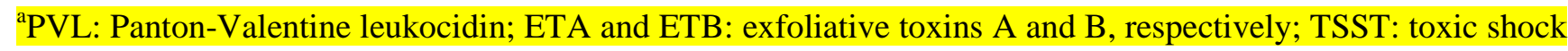
syndrome toxin.

${ }^{b}$ PE: penicillin, TE: tetracycline, ST: streptomycin, KA: kanamycin, CP: ciprofloxacin, CL: chloramphenicol, OX: oxacillin, FX: cefoxitin, ER: erythromycin, SX: trimethoprim-sulfamethoxazole.

${ }^{\mathrm{c}}$ This strain was obtained from individual which had contact with hospitalized patients

${ }^{\mathrm{d}}$ This strain was obtained from individual which referred previous use of antibiotics 
UPGMA

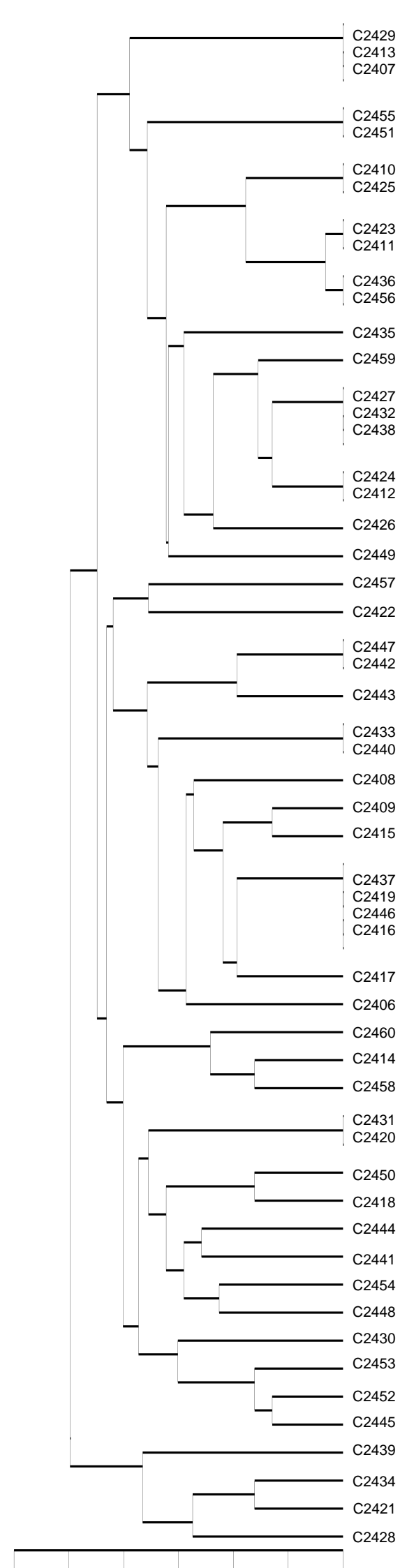

PFGE

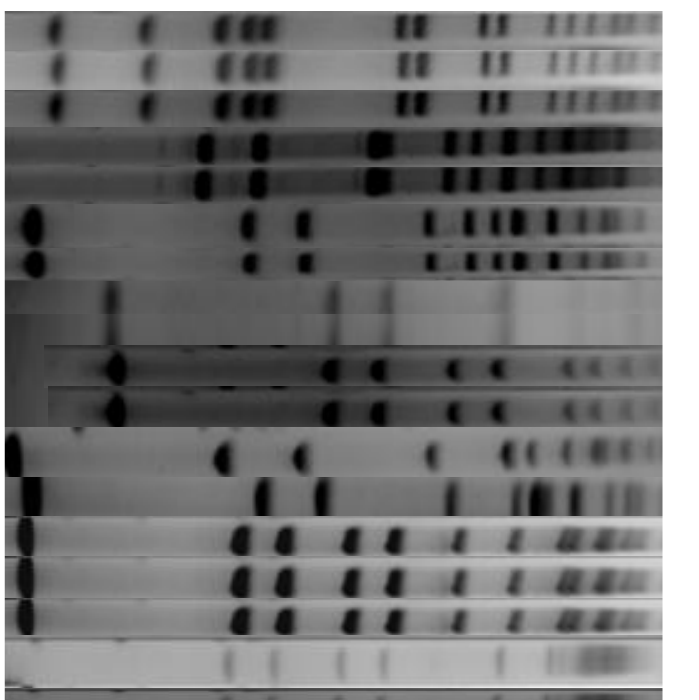$$
-
$$
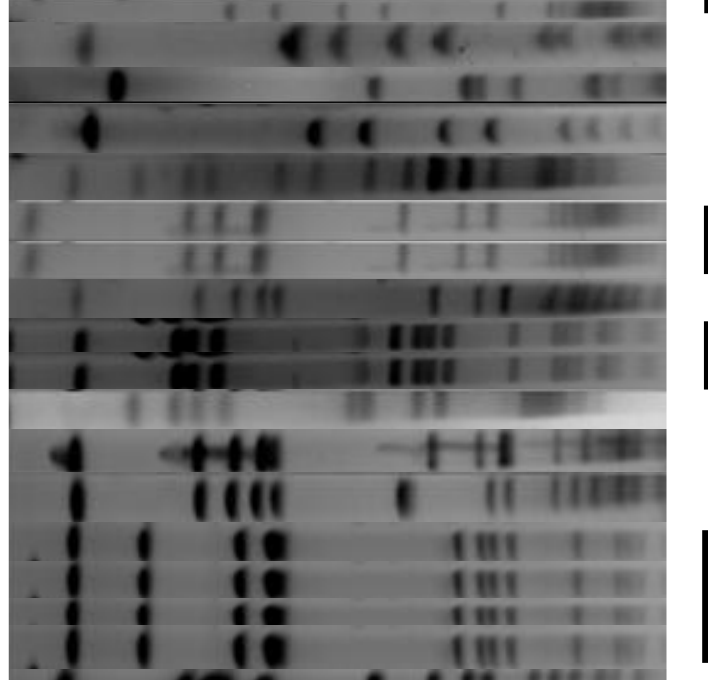$$
1
$$

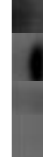

$$
\text { 政 }
$$

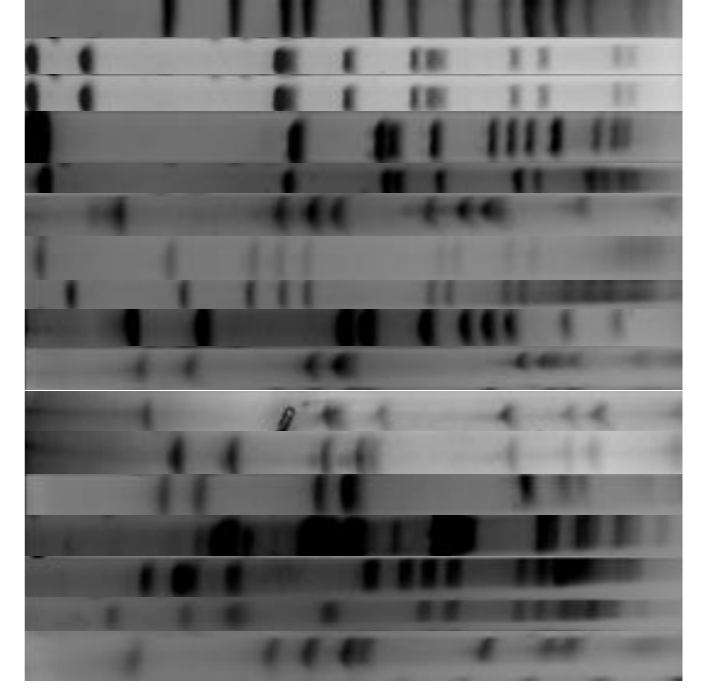

交 告

t002

t008

$\mathrm{t} 127$

t012

t018

t166

t166

t018

t012

t046

t012

t318

t6225

t230

t095

t6222

t701

t040

t1268

t223

t587

$\mathrm{t} 166$

t024

t024

t174

t084

t084

t537

$\mathrm{t} 254$

S13 t127

$\mathrm{t} 346$

t674

t094

t279

t559

t922

t559

t288

t166

$\mathrm{t} 159$

t254

t363

t709

t203

t6223

t701

t645

t254

t311

t224

t6224

t164

t377

t725

t711
TSST-1

TSST-1

TSST-1

TSST-1

TSST-1

TSST-1

ST30 PVL

New TSST-1

ST46 TSST-1

TSST-1

TSST-1

ETA,ETB

ETA

ST22 PVL

ST80 PVL

ST72

ST121 PVL

ST101

TSST-1

\section{$\begin{array}{lllllll}40 & 50 & 60 & 70 & 80 & 90 & 100\end{array}$}

Similarity (\%) 
Figure 1- Dendrogram displaying the grouping of 55 S. aureus isolates. Similarities are based on simple matching coefficient and UPGMA algorithm of SmaI macrorestriction profiles demonstrated by PFGE. 